\title{
LOW-ALLOYED ALLOYS ON THE BASE OF MOLYBDENUM, PREPARATION, PROPERTIES
}

\author{
Jaromír DRÁPALA, Marek VESELÝ, Gabriela KOSTIUKOVÁ, Monika LOSERTOVÁ, \\ Daniel PETLÁK
}

\author{
VSB - Technical University of Ostrava, Ostrava, Czech Republic, EU \\ Jaromir.Drapala@vsb.cz
}

https://doi.org/10.37904/metal.2019.939

\begin{abstract}
Literary research of high-temperature materials, overview of used materials. Molybdenum and its alloys, properties, possibilities of the application in the vacuum technique, electrotechnics and electronics. Methods of preparation of molybdenum alloys even in the monocrystalline form (plasma metallurgy and electron beam zone melting). Evaluation of micro-structural (optical microscope, scanning electron microscope), chemical (optical emission spectroscopy, x-ray and EDX analyses) of Mo-Ta, Mo-V and Mo-Ir alloys. Distribution of iridium in molybdenum by electron beam zone melting, dislocation and cellular substructure in molybdenum single crystals, application of autoradiography.
\end{abstract}

Keywords: Molybdenum alloys, crystal growth, microstructure, segregation, concentration undercooling

\section{INTRODUCTION}

Molybdenum is a refractory metal from VI.A group of the periodical system, it is silver-white colour, glossy; at its welding and forging is possible at elevated temperatures; it conduts electric current well.

Molybdenum metal is usually produced by powder metallurgy techniques in which Mo powder is hydrostratically compacted and sintered at high temperatures. Hot working is done in the $870-1260{ }^{\circ} \mathrm{C}$ range. Molybdenum forms a volatile oxide when heated in air above about $600^{\circ} \mathrm{C}$ and therefore high temperature applications are limited to non-oxidizing or vacuum environments. Molybdenum alloys have excellent strength and mechanical stability at high temperatures (up to $1900{ }^{\circ} \mathrm{C}$ ). Their high ductility and toughness provide a greater tolerance for imperfections and brittle fracture than ceramics.

The unique properties of molybdenum alloys are utilized in many applications: high temperature heating elements, radiation shields, extrusions, forging dies; rotating X-ray anodes used in clinical diagnostics; glass melting furnace electrodes and components that are resistant to molten glass; heat sinks with thermal expansivity matching silicon for semiconductor chip mounts; sputtered layers $10^{-7} \mathrm{~mm}$ thick for gates and interconnects on integrated circuit chips [1].

For specialised applications, Mo is alloyed with many other metals. Mo is clad with copper to provide low expansion and high conductivity electronic circuit boards. Mo- $25 \mathrm{wt} \%$ rhenium alloys are used for rocket engine components and liquid metal heat exchangers which must be ductile at room temperature [1,2]. Low alloyed molybdenum alloys it is possible to use as constructional elements in the field of vacuum electrical engineering, as thermocouples for temperature measuring till $2200^{\circ} \mathrm{C}$, as heating elements for resistant electrical furnaces. Essential demand on alloys molybdenum is their physical - chemical stability and inactivity against working atmosphere at high temperatures (approximately $2000^{\circ} \mathrm{C}$ ).

For refining and preparation of crystals of high purity molybdenum and its alloys plasma or vacuum arc melting with a horizontal water-cooled copper crystallizer can be used $[3,4]$. Molybdenum manufactured by powder metallurgy is used as an initial material. Obtained crystals have a coarse-grained structure with column grains elongated in the direction of crystallization. A rather better structure perfection of molybdenum can be achieved using plasma heating with a vertical crystallizer, where rod-shaped material is fed into the plasma stream and is melted, and metal droplets impinging onto the molten bath surface result in gradual crystallization. By using 
this method even low-alloyed molybdenum alloys with a single-crystalline structure can be prepared, where, after the metallographic preparation and proper etching, subgrains of different sizes with a relatively high concentration of dislocations due to high temperature gradients in the melting furnace can be found [3,4]. Crystal diameter can be up to $50 \mathrm{~mm}$ [5]. The electron-beam zone melting in high vacuum (the floating zone method - FZ) can be preferably used for preparation of molybdenum quality single crystals with a required crystallographic orientation. In this case crystal diameters are smaller (approximately to $15 \mathrm{~mm}$ ), however, the structure perfection is significantly higher $[3,4,6]$.

\section{THEORY}

Table 1 shows some physical properties of molybdenum, tantalum, vanadium and iridium.

Table 1 Selected physical properties of Mo, Ta, $\mathrm{V}$ and Ir $[3,7,8]$

\begin{tabular}{|c|c|c|c|c|c|c|}
\hline Metal & $\begin{array}{c}\text { Atomic } \\
\text { weight }\end{array}$ & $\begin{array}{c}\text { Atomic radius } \\
\boldsymbol{r}_{\boldsymbol{A}}(\mathrm{pm})\end{array}$ & $\begin{array}{c}\text { Density } \boldsymbol{\rho} \\
\left({\left.\mathrm{g} . \mathrm{cm}^{-3}\right)}\right.\end{array}$ & $\begin{array}{c}\text { Melting point } \\
\boldsymbol{T}_{\boldsymbol{M}}\left({ }^{\circ} \mathrm{C}\right)\end{array}$ & $\begin{array}{c}\text { Vapour presure } \\
\text { at } \boldsymbol{T}_{\boldsymbol{M}}(\mathrm{Pa})\end{array}$ & Structure \\
\hline Molybdenum & 95.94 & 139 & 10.2 & 2623 & 3.6 & $\mathrm{BCC}$ \\
\hline Tantalum & 180.95 & 146 & 16.6 & 3020 & 0.8 & $\mathrm{BCC}$ \\
\hline Vanadium & 50.94 & 134 & 6.1 & 1910 & 0.32 & $\mathrm{BCC}$ \\
\hline Iridium & 192.2 & 180 & 22.4 & 2446 & & $\mathrm{BCC}$ \\
\hline
\end{tabular}

\subsection{Binary system molybdenum - tantalum}

The Mo - Ta system binary diagram illustrates the "ideal" behaviour, when tantalum increases the melting point of molybdenum monotonously and both the metals create a solid solution within the entire range of concentrations [7]. The system was subject to an analysis. Modelling of solidus and liquidus curves including the thermodynamic control was carried out. Figure 1 shows a result of the modelling which implies a quite good conformity between the calculated course of the solidus and liquidus curves and the published diagram. The limit value of the equilibrium distribution coefficient $k_{o} \lim =1.03$, which means that a fairly good homogeneity of alloys can be achieved after the melting process.
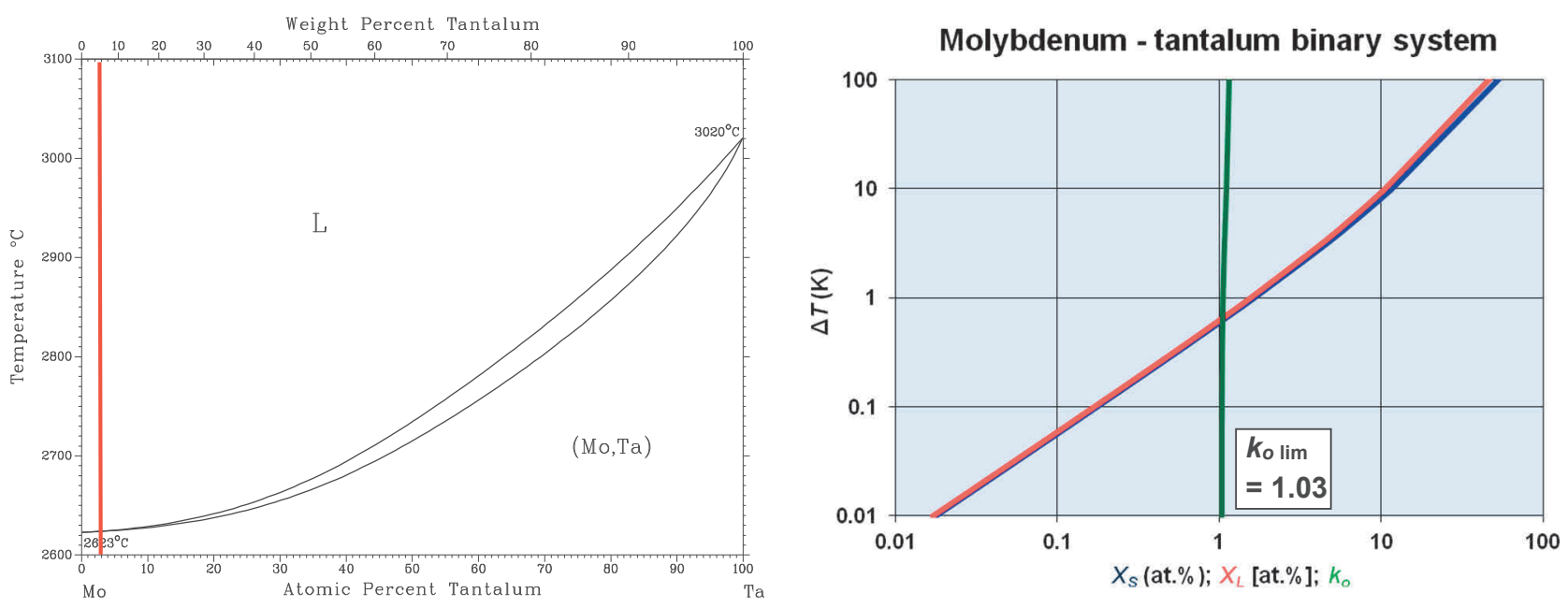

Figure 1 Molybdenum - tantalum binary system [7] and bilogarithmic projection $\Delta T=f\left(X_{S}, X_{L}, k_{\circ}\right)$

\subsection{Binary system molybdenum - vanadium}

Mo - V binary system diagram is also of the "ideal type with a complete solubility of components both in the solid and liquid state. However, vanadium decreases the molybdenum melting temperature in the entire 
concentration range. Its distribution coefficient $k_{o}$ is smaller than one. During modeling of this system it was found out that the liquidus curve did not correspond thermodynamically, therefore its course was corrected through the modelling - see Figure 2. The limit value of the equilibrium distribution coefficient for vanadium in Mo $k_{o}$ lim $=0.62$ and was more or less constant within a wide concentration range, which means that relatively homogenous alloys can be obtained after the melting process.
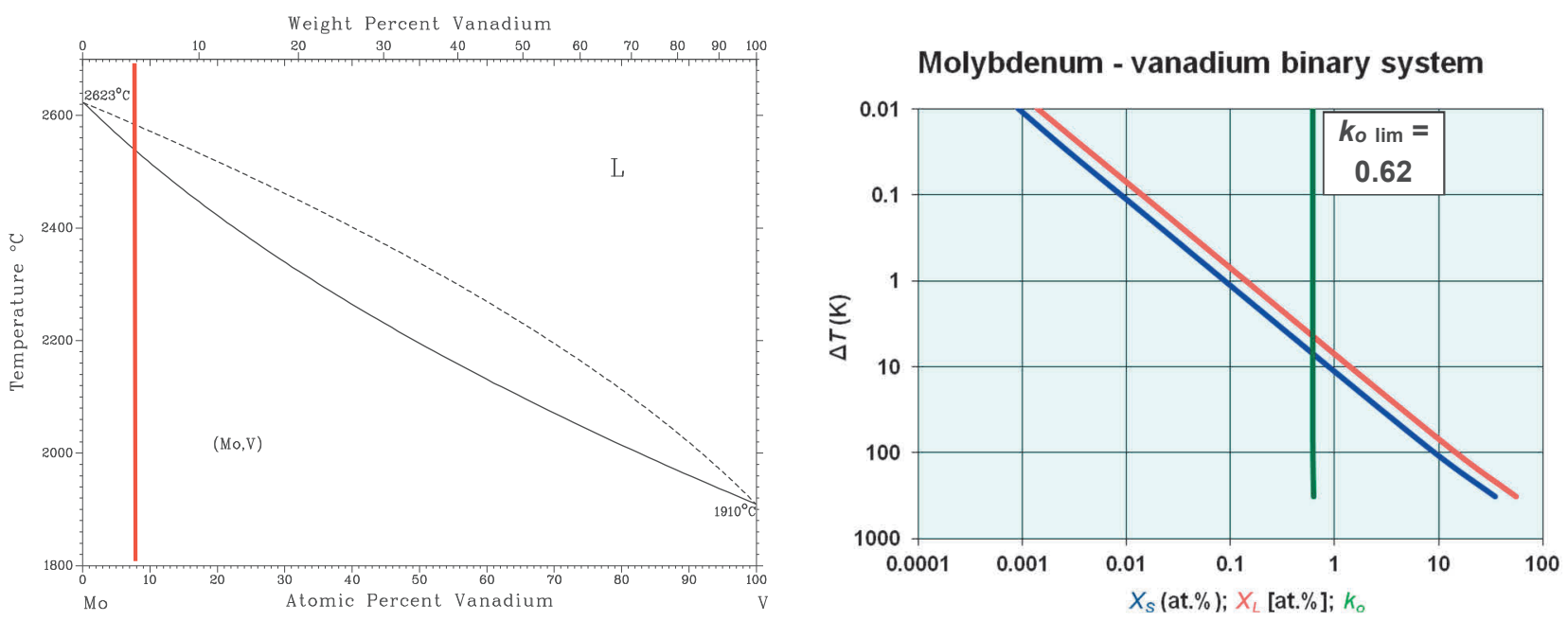

Figure 2 Molybdenum - vanadium binary system [7] and bilogarithmic projection $\Delta T=f\left(X_{S}, X_{L}, k_{\circ}\right)$

\subsection{Binary system molybdenum - iridium}

In the Mo - Ir system binary diagram on the molybdenum-rich side at the temperature of $2110{ }^{\circ} \mathrm{C}$ the peritectic reaction occurred resulting in $\mathrm{Mo}_{3}$ Ir phase formation. The liquidus curve dashed line has been plotted as the estimated one. The solidus and liquidus curves modelling on the molybdenum-rich side proved that the real liquidus curve would be moved slightly closer to solidus. The limit value of the equilibrium distribution coefficient for iridium in Mo $k_{o} \lim =0.26$, which means that inhomogeneities in iridium distribution and segregation in molybdenum can be expected during crystallization - Figure 3.
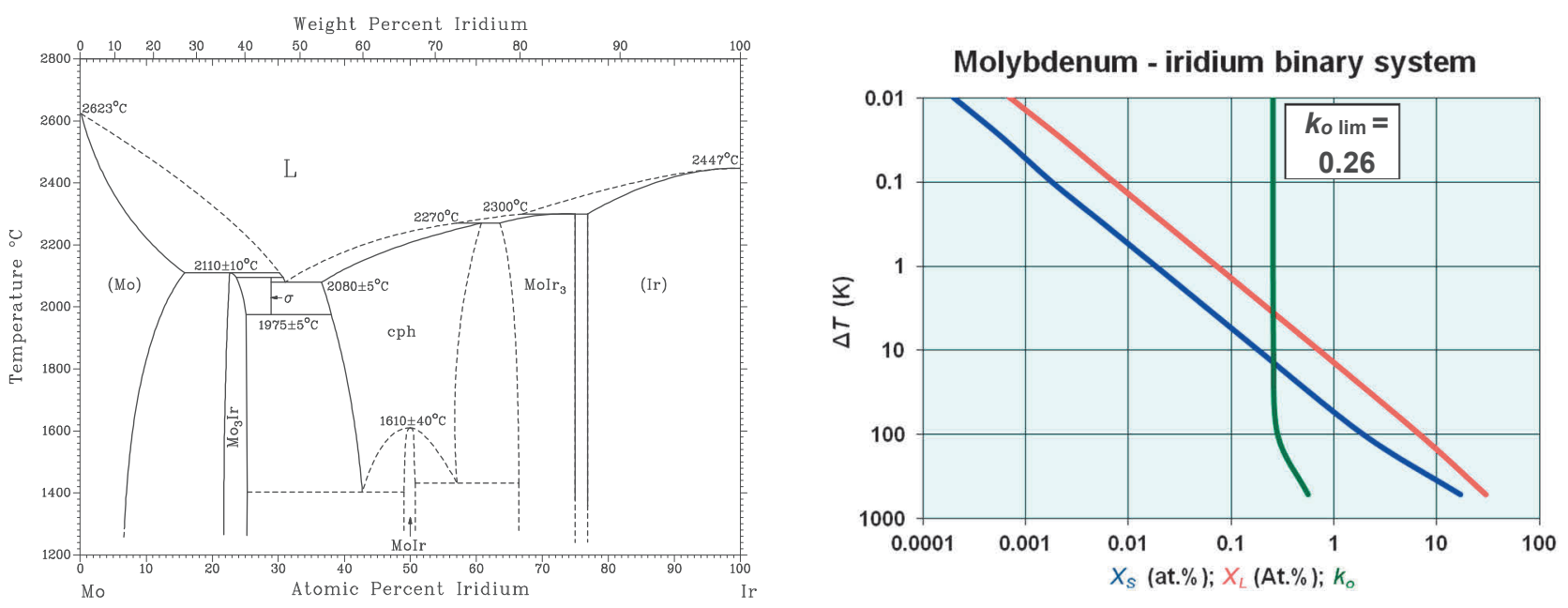

Figure 3 Molybdenum - iridium binary system [7] and bilogarithmic projection $\Delta T=f\left(X_{S}, X_{L}, k_{\circ}\right)$ 


\section{EXPERIMENT}

Within the experimental work molybdenum alloys with a low content of alloying elements vanadium, tantalum and iridium were prepared. Alloys with $4 \mathrm{wt} \% \mathrm{Ta}$ and $4 \mathrm{wt} \% \mathrm{~V}$ were synthesized using the plasma metallurgy method. Other molybdenum - iridium alloys were prepared in the electron-beam furnace using the FZ method. Specimens were subsequently subjected to the optical microscopy (macro- and microstructure), microhardness measuring, SEM / EDX microstructural and chemical analysis [8].

The initial material - molybdenum of $99.95 \%$ purity in a form of round bars - was manufactured in China and obtained from Germany over INKOSAS a.s., Prague, a Czech import/export company. Molybdenum was of a fine-grained polycrystalline structure with grain sizes of approximately $20 \mu \mathrm{m}$.

\subsection{Molybdenum - vanadium alloy}

The surface of Mo ingot with $4 \mathrm{wt} \% \mathrm{~V}$ was uneven after the plasma melting (synthesis). Irregularities were observed on the surface as well as across the cross-section, where cavities, pores and transversal cracks occurred - Figure 4. The observed structure resulted from uneven temperature distribution between the plasma affected molten metal surface (the temperature higher than $2800{ }^{\circ} \mathrm{C}$ ) and the bottom part of the specimen which was in a contact with the water cooled copper tray (the temperature about $20^{\circ} \mathrm{C}$ ). The plasma melting in the horizontal crystallizer is applicable in particular for preparation of pre-alloys of various metals; a required structure quality cannot be expected. The structure was coarse-grained with crystals elongated in the direction of the ingot longitudinal axis, i.e. in the direction of solidification. Formation of blow holes in the ingot resulted from an increased amount of the used argon during alloy melting in the plasma furnace (melt blowing).
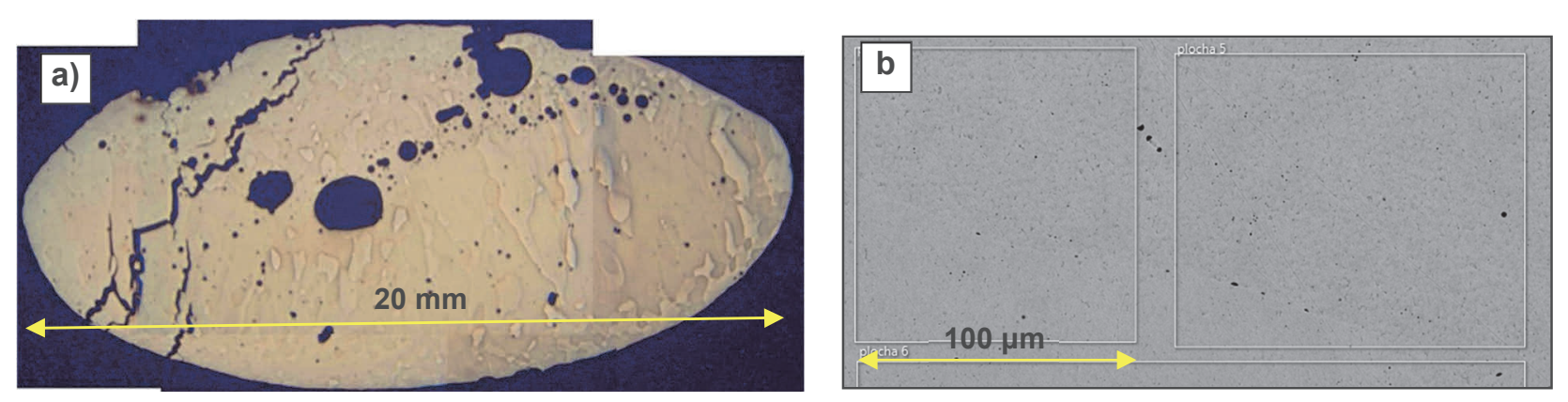

Figure 4 a) Macrostructure of Mo - 4 wt $\% \vee\left(H V_{0.1}=240\right)$; b) SEM image (3.99 wt $\%$ V - EDX analysis)

\subsection{Molybdenum - tantalum alloy}

A cross-section of the Mo - Ta remelted ingot following the plasma melting was uneven. Compared to Mo alloy with $4 \mathrm{wt} \% \mathrm{~V}$, the structure contained a negligible amount of fine blow holes (micropores) - Figure $\mathbf{5}$. The structure was coarse-grained.
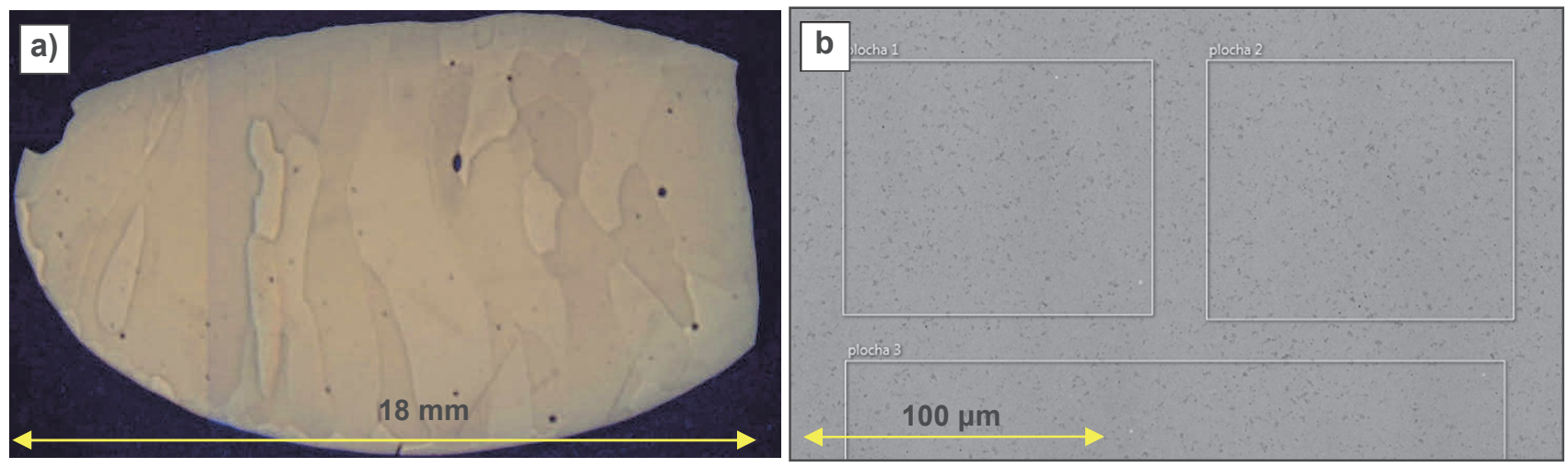

Figure 5 a) Macrostructure of Mo - 4 wt $\%$ Ta $\left(H \bigvee_{0.1}=225\right)$; b) SEM image (4.9 wt\% Ta - EDX analysis) 


\subsection{Molybdenum - iridium alloys}

The structural perfection, physical and plastic properties of single crystals prepared from the melt are conditioned above all by a type of the used material, its composition and purity and crystallization conditions, i.e. a shape and character of the crystal - melt phase interface, a type and intensity of convection in the melt, which is related to temperature and concentration gradients in the melt volume, on the phase interface as well as in the solidified crystal. Occurrence of temperature and concentration undercooling of the melt can lead to a formation of a cellular structure or under boundary conditions even to a dendritic structure. Temperature gradients in the melt can cause occurrence of the natural buoyant convection (a density gradient in the melt), which can induce a formation of growth bands (the so-called B-bands) congruent in shape with the actual shape of the crystal - melt phase interface.

The electron-beam zone melting of refractory metals through FZ method is also characterized by the existence of the melt surface tension gradients, which are independent of the Earth's gravity in contrast to the buoyant convection. In this case the so-called Marangoni convection occurs in the melt $[9,10]$. This type of convection results in a formation of growth cores (B-cores) across the crystal transverse cross-section. B-bands and Bcores represent micro-inhomogeneities in the distribution of admixtures and alloying elements in crystals along the axial and radial direction, which has a crucial influence on a dislocation substructure and usable properties of single crystals.

Influence of the dependence of the concentration and character of admixtures distribution at different crystallization conditions on occurrence of concentration undercooling and dislocation substructure of molybdenum single crystals was studied experimentally in order to assess relations between the chemical inhomogeneity and structural defects and their effect on single crystal properties. Iridium was chosen as an alloying element owing to its applicable properties for application of autoradiography and X-ray topography and also thanks to its favourable distribution coefficient in molybdenum $k_{\circ}$ lim $=0.26$ - see Chapter 2.3.

The initial material for the experimental works was highly pure molybdenum in a form of bars with $4 \mathrm{~mm}$ diameter and $100 \mathrm{~mm}$ length. The electron-beam floating zone melting was performed under high vacuum conditions $\left(10^{-3} \mathrm{~Pa}\right)$ at a zone movement velocity of $5 \cdot 10^{-3} \mathrm{~cm} \cdot \mathrm{s}^{-1}$. The orientation of the single crystal longitudinal axis was always <100>. The iridium concentration along the bar length was increasing continuously from $0 \%$ at the beginning of the bar to 2 at $\%$ at the end of the bar.

A character of the iridium distribution in molybdenum prepared without a seed rotation was studied autoradiographically. In addition, microphotometry of autoradiographs and X-ray microanalysis on MS-46 analyzer was used. Autoradiographs of specimens of single crystal longitudinal and transverse sections were obtained after the thermal neutron activation of specimens and 20-day dead time. For ${ }^{192} \mathrm{Ir}$ isotope, strongly blackened locations in negative images corresponded to areas with an increased concentration of iridium. Photographs of crystal surfaces and a classical metallography of transverse sections were obtained using Neophot 2 microscope. X-ray topography method was used to determine the structure perfection of single crystals. The following images show some selected results of the metallographic and autoradiographic studies of Mo-Ir single crystals substructures with various Ir contents, both in the longitudinal and transverse sections (Figures 6 - 8). In autoradiographic images of Mo-Ir single crystals the exposed locations were detected (areas of lighter colour in positive images) - the presence and character of the iridium distribution in the molybdenum matrix.

A formation of an extensive network of subgrains with a relatively high dislocation density, resulted probably from high thermal tensions, was observed at low iridium concentrations ( $<0.02 \mathrm{at} \% \mathrm{Ir}$ ) - Figure 6 . The transition area where first protrusions began to form on the solidus - liquid phase interface occurred at concentrations of 0.1 to 0.2 at\% Ir (Figure 7). Further increase in the iridium concentration resulted in a formation of the cellular structure. Subgrain boundaries had a smaller misorientation angle. 

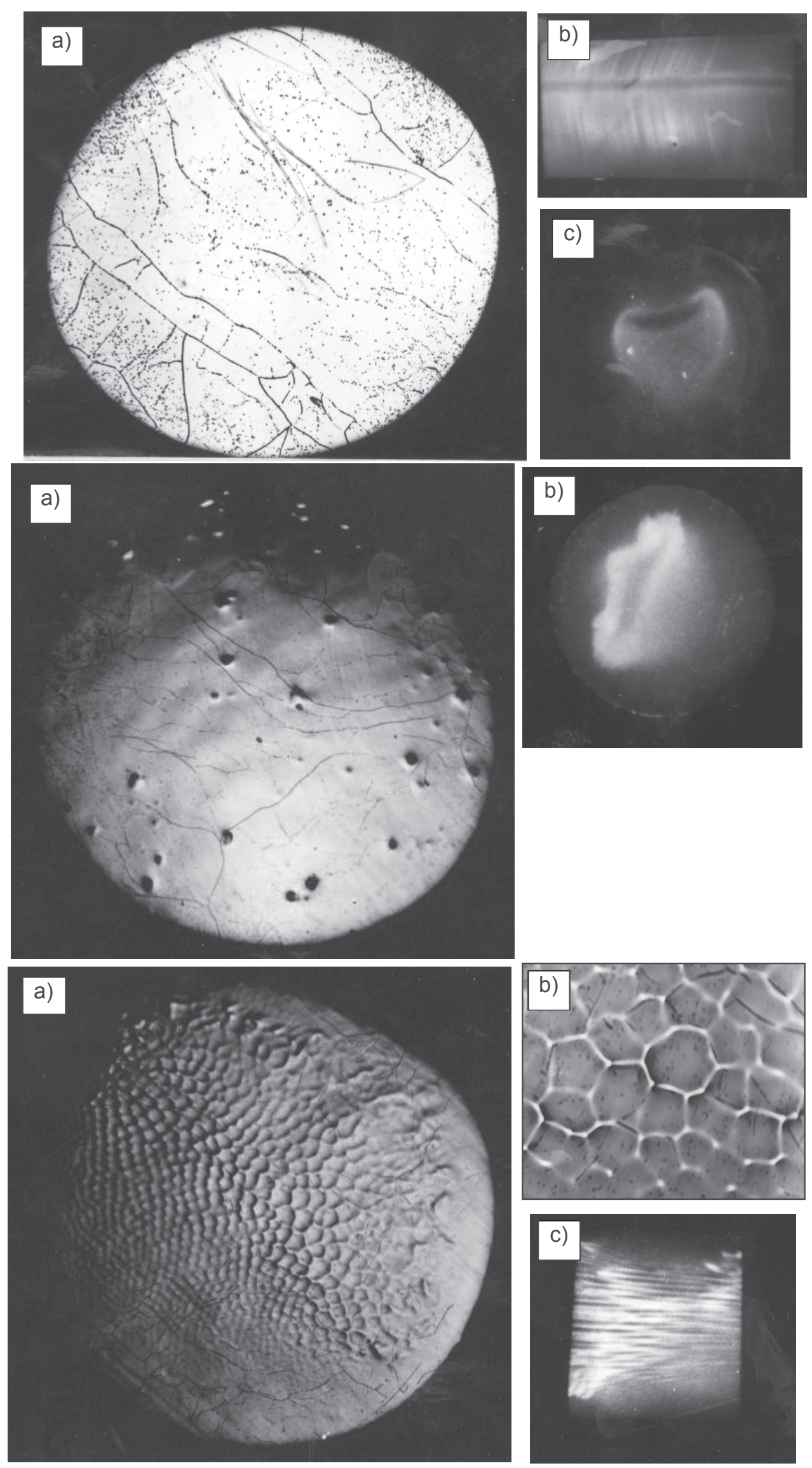

Figure 6 Alloy Mo - 0.05 at $\%$ Ir, single crystal diameter $4 \mathrm{~mm}$.

a) macrostructure of cross section. The extended dislocation substructure with visible boundaries of sub-grains;

b) autoradiograph of longitudinal section in Mo crystal documenting cross growth bands B-type;

c) autoradiograph of cross section.

Figure 7 Alloy Mo - 0.2 at $\% \mathrm{Ir}$, diameter $4 \mathrm{~mm}$.

a) macrostructure of cross section. The noses are found on the phase interface characterizing an initial stadium of cellular growth;

b) autoradiograph of cross section documenting high concentration of iridium in the central part of rod.

Figure 8 Alloy Mo - 0.8 at\% Ir, diameter $4 \mathrm{~mm}$.

a) Cross section.

Extended cellular structure of the hexagonal type.

b) microstructure of cross section. The increased concentration of Ir on the boundaries of cells;

c) autoradiograph of the longitudal section documenting cellularfilamentar structure. 
Cells occurred mainly in the central part of the crystal and featured a regular arrangement, whereas a minimum amount of dislocations were evident in the area of the cellular structure occurrence. The location of the cell area out of the crystal axis related to a slight heating asymmetry, which is a frequent accompanying phenomenon of crystallization particularly in a case of the electron-beam zone melting of alloyed crystals using a circular tungsten cathode. In a peripheral area of the crystal (near its surface) a formation of tiny subgrains could be still observed. A concentration above 0.6 at\% Ir induced a completely developed cellular growth more or less in the whole crystal volume with a high perfection of hexagonal cells and a low dislocation density (Figure 8).

The attached photo-documentation shows that iridium concentrated preferentially in the central area of the molybdenum single crystal, so near the bar surface molybdenum was iridium-depleted, which related to the temperature gradients in the melt. In conformity with theoretical presuppositions of crystallization, iridium tended to concentrate into a lower temperature zone, which, in the case of the electron-beam floating zone melting, occurred near the crystal axis. A surface of the melt (zone) had a higher temperature. Therefore here the matrix exhibited lower concentrations of those admixtures that have a distribution coefficient lower than one $(\mathrm{k}<1)$.

The growth cores concentrated near the crystal axis in a case of admixtures with $k<1$ occurred at concentrations above 0.2 at\% Ir, when the cellular growth gradually became dominant (transverse growth bands of B type faded away completely). At a further increase of the iridium concentration above 0.6 at $\%$ the cellular structure area expanded into the whole crystal volume. Under these concentration conditions (considerable concentration underrcooling) the phase interface consisted of regularly located protrusions with a lower iridium concentration along axes of the protrusions surrounded by the matrix melt enriched with iridium. This melt in intercellular spaces crystallized last, thus an increased iridium concentration could be observed in contact places of two hexagonal cells. At a constant zone length $b=4 \mathrm{~mm}$ a limiting concentration of iridium was found $C^{*} \approx 0.2$ at\% $\mathrm{Ir}$, when a smooth surface of the phase interface lost its stability (Figure 7 a), protrusions into the melt occurred, as well as irregular cells in a single crystal transverse cross-section and a cellular - filamentary structure along the longitudinal direction. Iridium concentrated in the central area of the crystal (Figure 7 b).

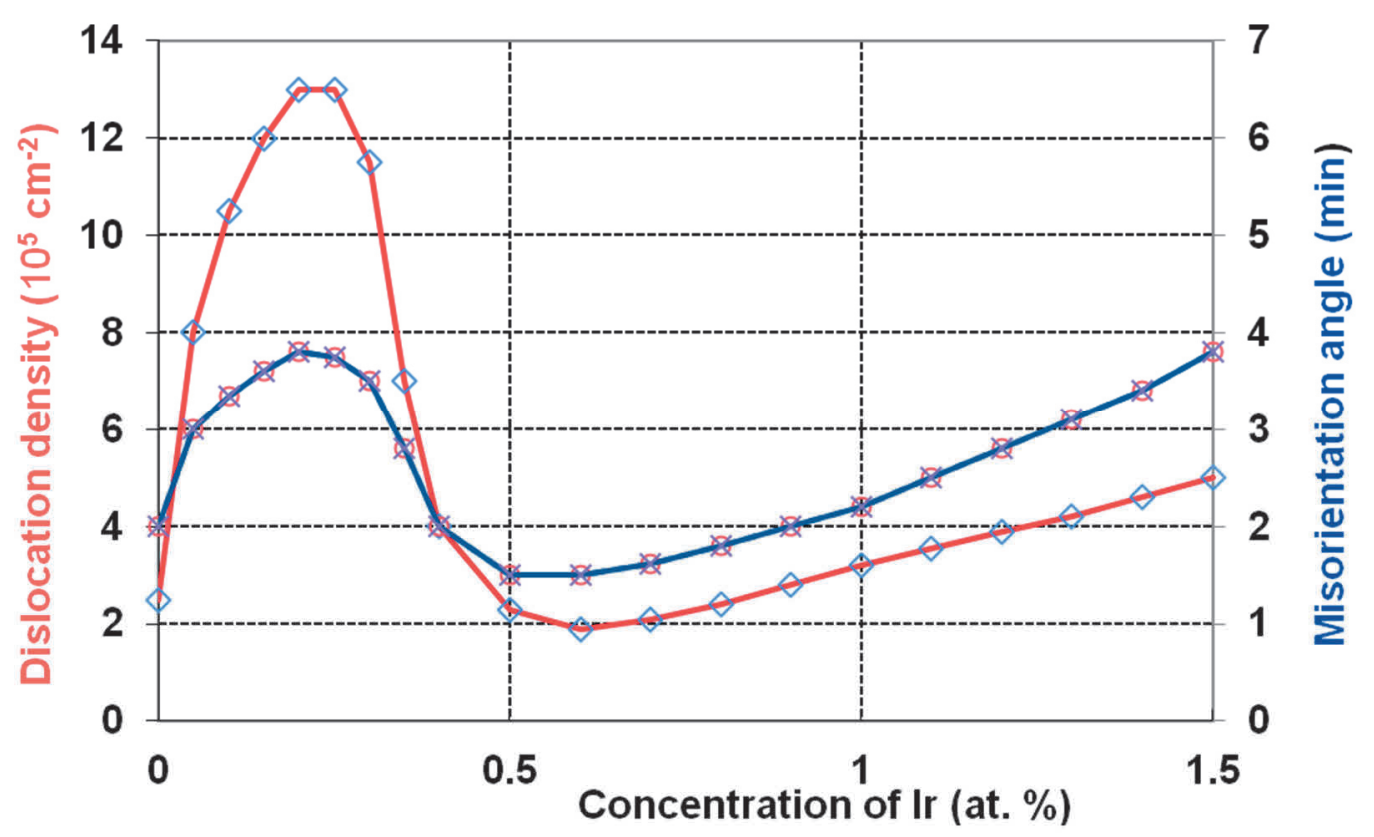

Figure 9 Dependencies of dislocation density and misorientation angle of subgrains on the concentration of iridium in molybdenum single crystals 
At a concentration above 0.4 at\% Ir an almost perfect cellular substructure was observed (Figures 8, 9) and the dislocation density and misorientation degree of adjacent subgrains reached a state that corresponded to pure molybdenum. It was found out that in a purely cellular growth the iridium concentration along the radial direction of the crystal exhibited an oscillation character with a maximum Ir concentration on cell boundaries $(0.6 \mathrm{at} \% \mathrm{Ir})$ and with a minimum inside the cells $(0.3 \mathrm{at} \% \mathrm{Ir})$, whereas one cell dimension was equal to approximately $0.1 \mathrm{~mm}$. The structure recovery was caused by the fact that dislocations of opposite signs could annihilate at high temperatures within a distance of one cell, thus leading to the dislocation density reduction and an increase in structure perfection of crystals. However, this was possible only at sufficiently high movability of dislocations, i.e. in the initial stage of cell formation.

When increasing molybdenum alloying up to $1.5 \mathrm{at} \% \mathrm{Ir}$, the crystal substructure perfection decreased again. Concentration gradients on cell boundaries increased, therefore the dislocation formation probability would be higher. Their movability decrease while Ir content increasing resulted in a decrease in dislocation annihilation ability. This resulted in a dislocation density increase and a crystal perfection decrease. Figure 9 shows that the dislocation density in the area of Ir concentrations above 0.6 at $\%$ increased almost linearly along with its concentration up to 1.5 at $\%$ Ir.

\section{CONCLUSION}

Molybdenum alloys with tantalum (4 wt\%) and vanadium (4 wt \%) were prepared using the plasma metallurgy. The alloys structure was coarse-grained with large grains elongated along the transversal as well as longitudinal direction of the ingot. The vanadium and tantalum distribution in molybdenum following the plasma melting was homogenous. No phases were identified in the microstructure of alloys. In the next stage remelting of both the alloys in the plasma furnace with a vertical crystallizer was planned in order to obtain a round ingot with a diameter of $20 \mathrm{~mm}$ that was subsequently formed to rods with a diameter of 6 to $8 \mathrm{~mm}$ using the rotational forging technology. Then these rods were remelted in the electron-beam vacuum furnace using FZ method in order to obtain Mo-V and Mo-Ta alloys single crystals that were subjected to a complex analysis afterwards.

Various types of micro-inhomogeneities occurred in highly pure molybdenum based Mo-Ir single crystals with the axis orientation $<100>$ prepared by electron-beam floating zone melting under conditions without a seed rotation depending on Ir concentration from 0.01 to 1.5 at $\%$ Ir: B-bands, B-cores and a cellular - filamentary structure. Radial inhomogeneities consisting of growth cores and related concentration gradients increased along with an increase of the concentration up to the critical value $C_{c r}=0.4 \mathrm{at} \% \mathrm{Ir}$, when a developed cellular - filamentary structure occurred. At concentrations above $C_{c r}$ the oscillation of concentration gradients on cell boundaries increased.

For the preparation of alloyed single crystals of refractory metals with a high physical perfection the following conclusions need to be taken into account:

a) The zone length (the melt volume) determines the prevailing type of the natural buoyant convection or Marangoni convection. In both the cases, when exceeding the critical zone length, microinhomogeneities occur in the crystal in a form of growth bands or growth cores.

b) Below $C_{c r}$, both the amount of admixtures and their distribution in the radial direction influence the structure of crystals.

c) At certain concentrations of alloying elements the cellular - filamentary structure can reach a high structure perfection of crystals.

d) Above $C_{c r}$, concentration gradients of B-cores have a significant influence on a perfection of crystals. They induce a formation of an inhomogeneous substructure with a high dislocation density in the crystal peripheral areas. 
e) B-cores can be eliminated significantly through the forced convection (rotation, an external magnetic field etc.).

f) The substructure of single crystals is influenced substantially by thermal tensions.

\section{ACKNOWLEDGEMENTS}

This work was elaborated on the basis of the international scientific cooperation in the research performed in the Baikov Institute of Metallurgy and Materials Science, RAS, and in the Faculty of Materials Science and Technology at the VŠB - Technical University of Ostrava. Melting aggregates in laboratories of the Regional Materials Science and Technology Centre and other diagnostic devices within the Faculty of Materials Science and Technology and the Department of Non-ferrous Metals, Refining and Recycling were used for this work.

This paper was funded by the Ministry of Education, Youth and Sports of the Czech Republic - the project SP2019/43 “Specific Research in the Metallurgical, Materials and Process Engineering”.

\section{REFERENCES}

[1] https://www.imoa.info/molybdenum-uses/molybdenum-metal-alloys.php.

[2] SHIELDS, John A. Applications of Molybdenum Metal and its Alloys. 2nd ed. London: International Molybdenum Association (IMOA), 2013, p. 42. ISBN 978-1-907470-30-1.

[3] LYAKISHEV, N.P., and BURKHANOV, G.S. Metallic Single Crystals. Moscow „ELIZ“, 2002, p. 312. In Russian.

[4] WILKINSON, Walter D. Fabrication of Refractory Metals. New-York-London-Paris: Argonne National Laboratory, 1975, $344 \mathrm{p}$.

[5] BURKHANOV, G.S., SHISHIN, V.M., KUZMISHCHEV, V.A. and SHNYREV, G.D. Plasma Metallurgy of Refractory Metals. Moscow: Metallurgy, 1981. p. 198. In Russian.

[6] BRODSKIY, J.A. et all. Molybdenum and Tungsten Single Crystals. Tashkent: FAN Uzb. SSR, 1973. In Russian.

[7] MASSALISKI, Thaddeus B. Binary Alloy Phase Diagrams. On CD-ROM. Version 1.0. Materials Park, Ohio: ASM International, 1996. ISBN 0-87170-562-1.

[8] VESELÝ, Marek. Low Alloyed Alloys Based on Molybdenum for Applicatinos in Electrical Engineering. Thesis. Ostrava: VSB-TU Ostrava, 2019, p. 46.

[9] DRÁPALA, J. Electron Metallutgy of Refractory Metals, Alloys and Compounds. Habilitation, VSB-TU Ostrava, 1994, p. 104. In Czech.

[10] KUCHAŘ, Lumír, HEIN, Klaus., BUHRIG, Eberhard and BARTHEL, J. Kristallisation aus Schmelzen. Leipzig: VEB Deutscher Verlag für Grundstoffindustrie. 1983, p. 356. In German. 